\title{
From Notion to Reality: The Creation of a New Student Medical Journal
}

\section{The Notion}

It began simply as an idea with promise. While searching for a project to pursue during the summer after my first year of medical school at McGill University, I was impressed by the wealth of opportunities available to medical students interested in research. At McGill, there was also a forum called "Student Research Day," an annual scientific meeting allowing medical students to showcase their work by presenting their results to the local healthcare community. The projects presented were of high caliber, and certainly would have been of interest to a wider audience. I was struck by the thought that a medical journal presenting solely student work would have provided the means for recognizing this work on a larger scale.

Since students may already submit their work to existing professional medical periodicals for publication, is there a need for a new journal that promotes solely student contributions to medical science? My answer is an emphatic "yes." I am convinced that students can make noteworthy contributions to medical knowledge through their participation in research activities. A single publication presenting work exclusively by students would serve notice that they can make a difference in the research community.

A student journal may also encourage individuals who are relatively new to research to submit their work for publication for the first time, a process that might serve as an important stepping stone and incentive for further research endeavors. For aspiring student authors, the rewards of seeing one's name in print are apparent, but the process of conducting research, analyzing data, and preparing a manuscript for publication are the truly enriching aspects of the experience. A new journal focusing primarily on student authorship may also provide them with increased opportunities to receive the public recognition they deserve for pursuing independent work (1). For the student editors and publications staff, there would be additional educational benefits associated with the production of the journal.

According to a study by Taylor, it was estimated that approximately 42 hours per week are required for second year medical students at the University of Southern California to complete the assigned readings (2). Keeping pace not only with the demanding workload of the medical curriculum but also with the continuously expanding literature would be a task of Herculean proportions for potential authors and editors alike.

However, scientific inquiry lies at the heart of medical progress. We students in the health sciences have a vested interest in medical research pursuits, the reductionist or microscopic approaches to solving problems in medicine. One day, the mantle of responsibility will be placed on our collective shoulders to find cures for illnesses such as AIDS, cancer, Alzheimer's, and other chronic conditions that defy straightforward treatments. As the physicians and scientists of tomorrow, we have an obligation to remain on the forefront of current research efforts.

It is equally important for us to remain active in health policy, disease prevention and control, and other macroscopic approaches to current medical problems. The environment of uncertainty surrounding universal healthcare coverage in the United States, increasing restrictions on manpower mobility in Canada, and other 
important issues that impact the future of medicine are of vital concern to students everywhere. We cannot afford to simply learn or practice medicine in an intellectual vacuum.

A journal would facilitate discussions regarding important medical issues and nurture student participation in both micro- and macroscopic endeavors that could potentially lead to beneficial outcomes in the medical community. For these reasons, I was inspired by the idea of starting a new student medical journal. Ideas inspire people to move in surprising new directions. Without knowing it, my colleagues and I were about to enrich our medical studies by embarking on the exciting enterprise of creating a new journal from scratch.

\section{The Foundation}

In May 1994, I submitted a proposal elaborating the idea of a new medical journal for students to the Deans at the McGill Faculty of Medicine. They officially approved our organization approximately two weeks later. Thus was born the McGill Journal of Medicine (MJM), a new student medical journal.

The MJM is an independent organization run entirely by students at McGill University. Since the first general meeting in which 17 people in my class attended, our editorial board has grown to include the 52 students listed in the masthead on the inside front cover of this journal. These include first- and second-year medical students in the Faculty of Medicine, first-year students pursuing M.B.A. degrees in the Faculty of Management, and undergraduate and graduate students in the Faculties of Arts and Sciences.

We students run the entire spectrum of editorial production, from evaluating and reviewing the scientific content of manuscript submissions, to copy-editing and typesetting the final papers. On the business side, we sell advertising space and subscriptions, seek financial support in the form of donations and grants, market the journal to expand the readership and sponsorship base, solicit manuscripts, and distribute final copies of the journal to medical libraries, institutions, and individual subscribers. All of these phases of production have provided our staff with an incredible learning experience regarding the mechanisms of journal production.

As a resolute editorial board, we presented the concept of a medical journal for students to individuals and organizations in the McGill and local communities. The McGill Computer Store, the first financial Founder of the McGill Journal of Medicine, donated a complete package of computer hardware and software sufficient for our graphics, design, and layout needs. Our other financial Founder, the Bank of Nova Scotia, along with the other companies, organizations, and individuals recognized in the Acknowledgements section of this journal, collectively contributed nearly $\$ 30,000$ towards the successful establishment of the MJM.

The realization of a project of this magnitude less than one year after its inception reflects how responsive people have been to the mere idea of this publication. The students who have submitted articles for publication and have participated in the production of the journal, the faculty members who have volunteered their time to serve as referees for manuscript submissions, and the numerous individuals and organizations in the McGill and local communities who have made material and monetary donations all have contributed solely on the basis of an idea with promise. We had nothing tangible to offer them, just an idealistic concept; but this was enough to convince each and every one of them that their support for the MJM would be worthwhile. We are grateful for their generosity and faith in the idea which made the publication of this premiere issue a reality.

\section{The Reality}


The McGill Journal of Medicine is an international forum for the advancement of medical science by students. Our objective is to provide student authors with opportunities to voice their contributions to medicine in one scholarly, biannual publication. Towards this end, we intend to publish original research and review articles relevant to the field of medicine. Our authors will represent undergraduates in bachelor's degree programs, and graduate students in master's, doctoral, or healthcare degree programs (medicine, dentistry, nursing, physical and occupational therapy, etc.).

Our intended readership will include physicians, scientists, residents, and university students in the health sciences around the world. However, among other medical scientific publications, the MJM has a unique and well-defined niche because it provides readers with a compendium of medical research accomplished exclusively by students, a feature that undoubtedly fills a void in the current arena of scientific publications.

The MJM intends to play a prominent role in recognizing and disseminating the efforts of students at institutions around the world who are making important contributions to medical science. We are grateful to the students across North America who took the initiative to submit their work for consideration in this premiere issue. The content of the final manuscripts accepted for publication reflects the broad scope of the MJM, ranging from original research articles related to clinical medicine, to articles that explore specific issues in basic science. We encourage the submission of review articles and letters because they promote the discussion of relevant issues in medicine. For the premiere issue, we are honored to have received a letter of support from one of our distinguished alumni of the McGill Faculty of Medicine, Dr. David Hubel, who received the Nobel Prize in Medicine in 1981.

There are two other features of the MJM that enhance its content. "Crossroads," a section of the journal highlighting the interplay between medicine and the humanities, presents articles that relate medicine to fields such as ethics, history, philosophy, and health policy. The other section, "MJM Focus," explores the scientific, clinical, and pathological features of a medical specialty of interest. In this issue, we focus on the medical subspecialty of "Allergy and Immunology" by presenting an invited basic science review (BSR) article written by a member of the McGill faculty, and a clinicopathological correlation (CPC) written by a resident at the Montreal General Hospital. The rationale behind this presentation is that the BSR hopefully will give readers a review of the background information necessary to understand the scientific principles underlying the clinical and pathological features of the condition described in the CPC. These sections are particularly relevant for a student audience, but will be interesting features for our readers who are established health science professionals. We intend to explore other medical specialties of interest in future issues of the journal, and may include profiles of the medical specialties that encounter and treat patients with similar cases to the ones presented in the CPCs.

\section{The Future}

It is my pleasure to present to you, on behalf of the editorial board, this premiere issue of the McGill Journal of Medicine (MJM). We hope you will share our enthusiasm for this new publication, whether you are a student reader interested in seeing what your colleagues around the world are contributing to medical science, or are an established physician, scientist, or other practicing member of the health sciences community interested in seeing what kind of work is being accomplished by the young physicians and scientists of tomorrow. Some of our future initiatives will be submitting the MJM for indexing in reference indices, producing the journal in electronic format, and adding to the "MJM Focus" the profiles of relevant medical specialties and the residency programs that offer them.

We invite all potential authors to submit manuscripts of original, review, or Crossroads articles, and encourage readers to voice any thoughts concerning current medical issues of interest. Please keep us 
informed of our progress with your feedback - this is, after all, your forum. With your continuing support and participation, our editorial board is committed to producing a quality publication. This journal began simply as an idea with promise. It is now the reality you hold in your hands.

Jonathan E. Lim, M.S.

Founding Editor

McGill Journal of Medicine

McGill University Faculty of Medicine

Montreal, QC, Canada H3G 1 Y6

1. Ward B. Undue Credit for Supervisors [letter]. Nature 1994;368:579.

2. Taylor CR. Great Expectations: The reading habits of year II medical students. New England Journal of Medicine 1992;326:1436-1440. 